\title{
Quinoxaline-Imidazolium Receptors for Unique Sensing of Pyrophosphate and Acetate by Charge Transfer
}

\author{
N. Jiten Singh, ${ }^{a}$ Eun Jin Jun, ${ }^{b}$ Kavitha Chellappan, ${ }^{a}$ Daniel Thangadurai, ${ }^{a}$ R. \\ Prakash Chandran, ${ }^{a}$ In-Chul Hwang, ${ }^{a *}$ Juyoung Yoon, ${ }^{b_{*}}$ Kwang S. Kim $^{a_{*}}$ \\ ${ }^{a}$ Center for Superfunctional Materials, Department of Chemistry, Pohang University of Science and \\ Technology San 31, Hyojadong, Namgu, Pohang, 790-784, Korea \\ ${ }^{b}$ Division of Nano Science and Department of Chemistry, Ewha Womans University,11-1 Daehyon-Dong, \\ Sodaemun-Ku, Seoul 120-750, Korea \\ spfe@postech.ac.kr,jyoon@ewha.ac.kr; kim@postech.ac.kr
}

Supporting Information -I

I. ${ }^{1} \mathrm{H}-\mathrm{NMR}$ and ${ }^{13} \mathrm{C}-\mathrm{NMR}$ of Compound $\mathbf{1}$

II. ${ }^{1} \mathrm{H}-\mathrm{NMR}$ and ${ }^{13} \mathrm{C}-\mathrm{NMR}$ of Compound $2 \quad$ S2

III. ${ }^{1} \mathrm{H}-\mathrm{NMR}$ and ${ }^{13} \mathrm{C}-\mathrm{NMR}$ of Compound $3 \quad \mathrm{~S} 3$

IV. ${ }^{1} \mathrm{H}-\mathrm{NMR}$ and ${ }^{13} \mathrm{C}-\mathrm{NMR}$ of Compound $4 \quad \mathrm{~S} 4$ 
I. ${ }^{1} \mathrm{H}-\mathrm{NMR}$ and ${ }^{13} \mathrm{C}$-NMR of Compound $\mathbf{1}$

Comp. $1\left({ }^{1} \mathrm{H}-\mathrm{NMR}\right)$
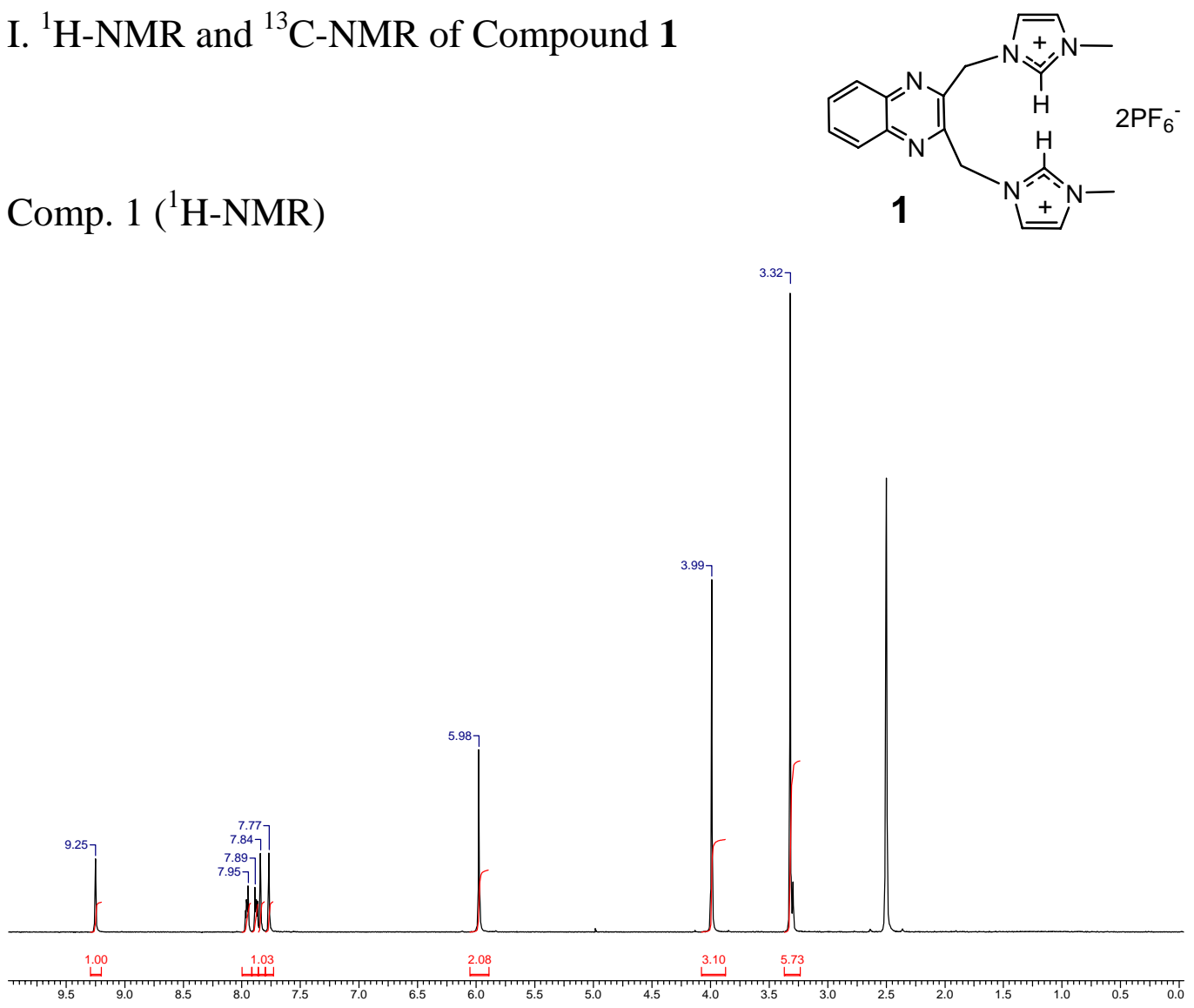

Comp. $1\left({ }^{13} \mathrm{C}-\mathrm{NMR}\right)$

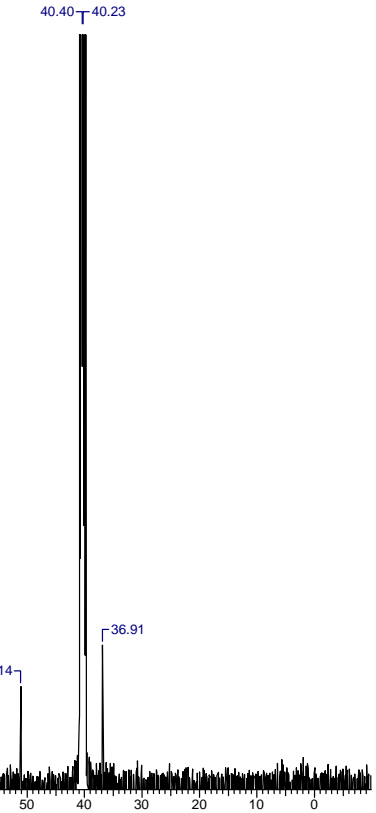


II. ${ }^{1} \mathrm{H}-\mathrm{NMR}$ and ${ }^{13} \mathrm{C}-\mathrm{NMR}$ of Compound 2

Comp. $2\left({ }^{1} \mathrm{H}-\mathrm{NMR}\right)$
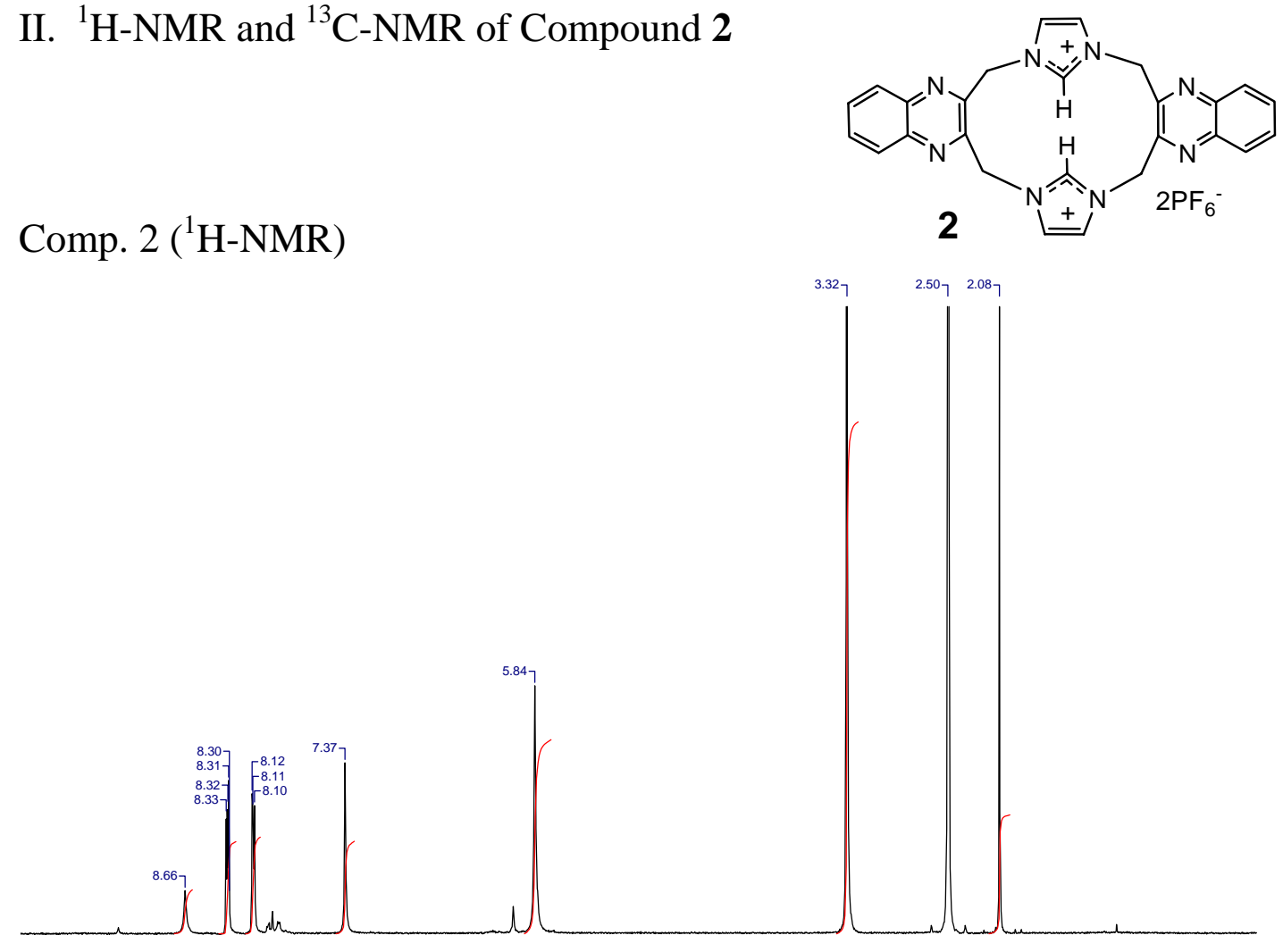

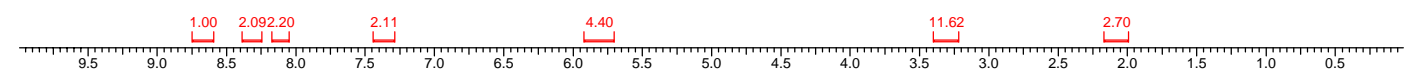

Comp. $2\left({ }^{13} \mathrm{C}-\mathrm{NMR}\right)$

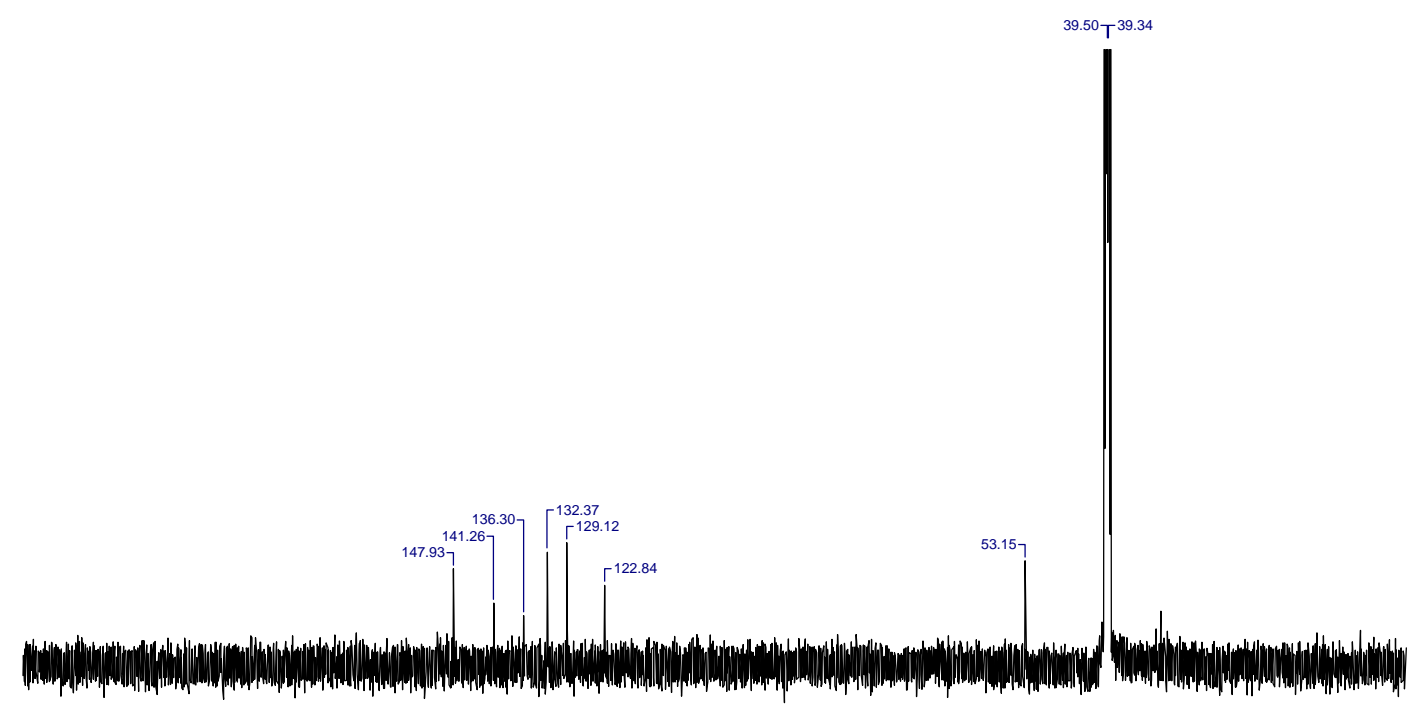

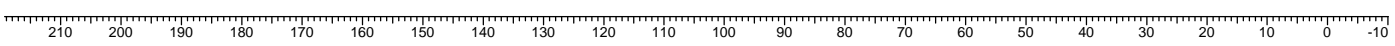


III. ${ }^{1} \mathrm{H}-\mathrm{NMR}$ and ${ }^{13} \mathrm{C}-\mathrm{NMR}$ of Compound 3

Comp. $3\left({ }^{1} \mathrm{H}-\mathrm{NMR}\right)$
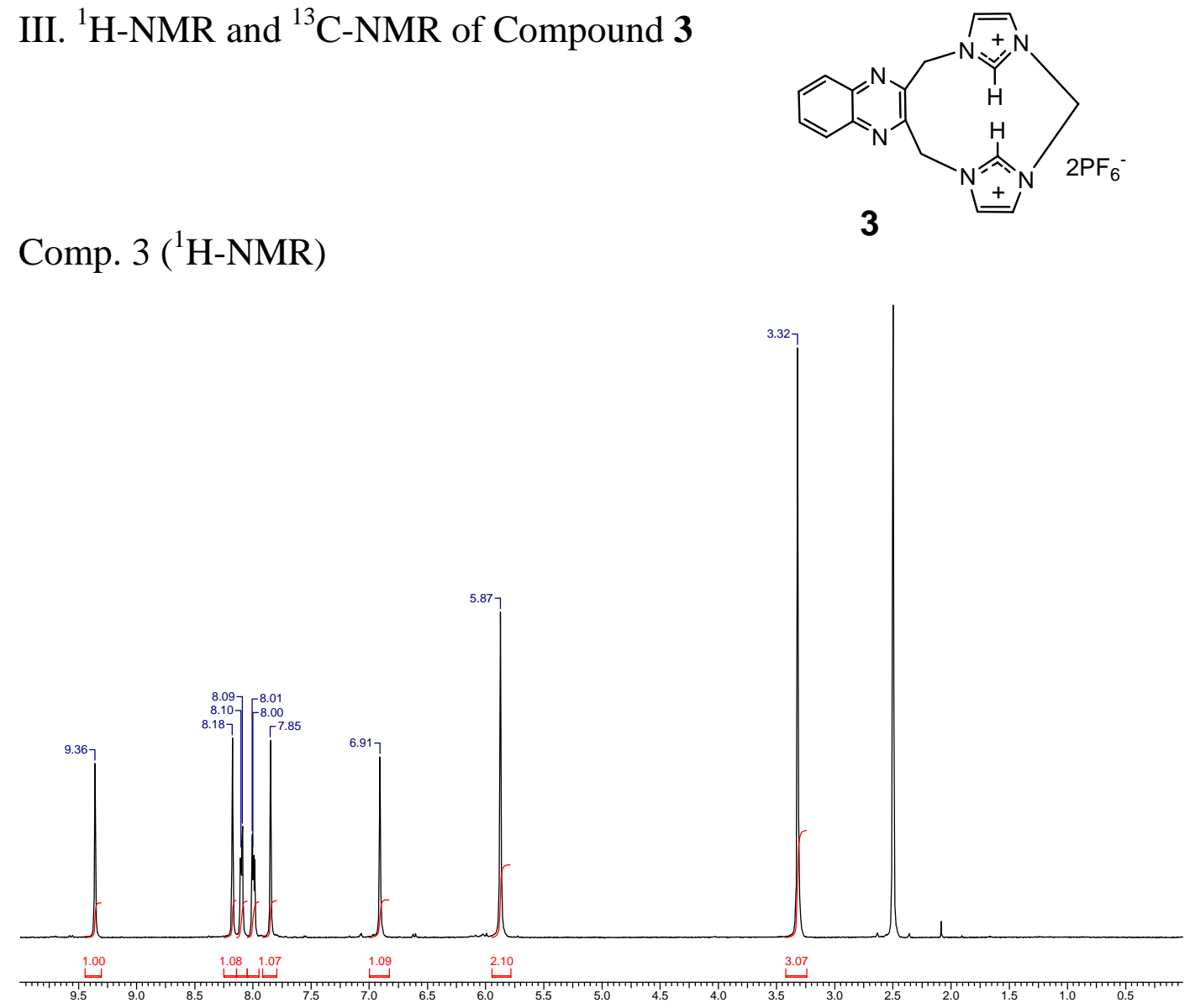

Comp. $3\left({ }^{13} \mathrm{C}-\mathrm{NMR}\right)$
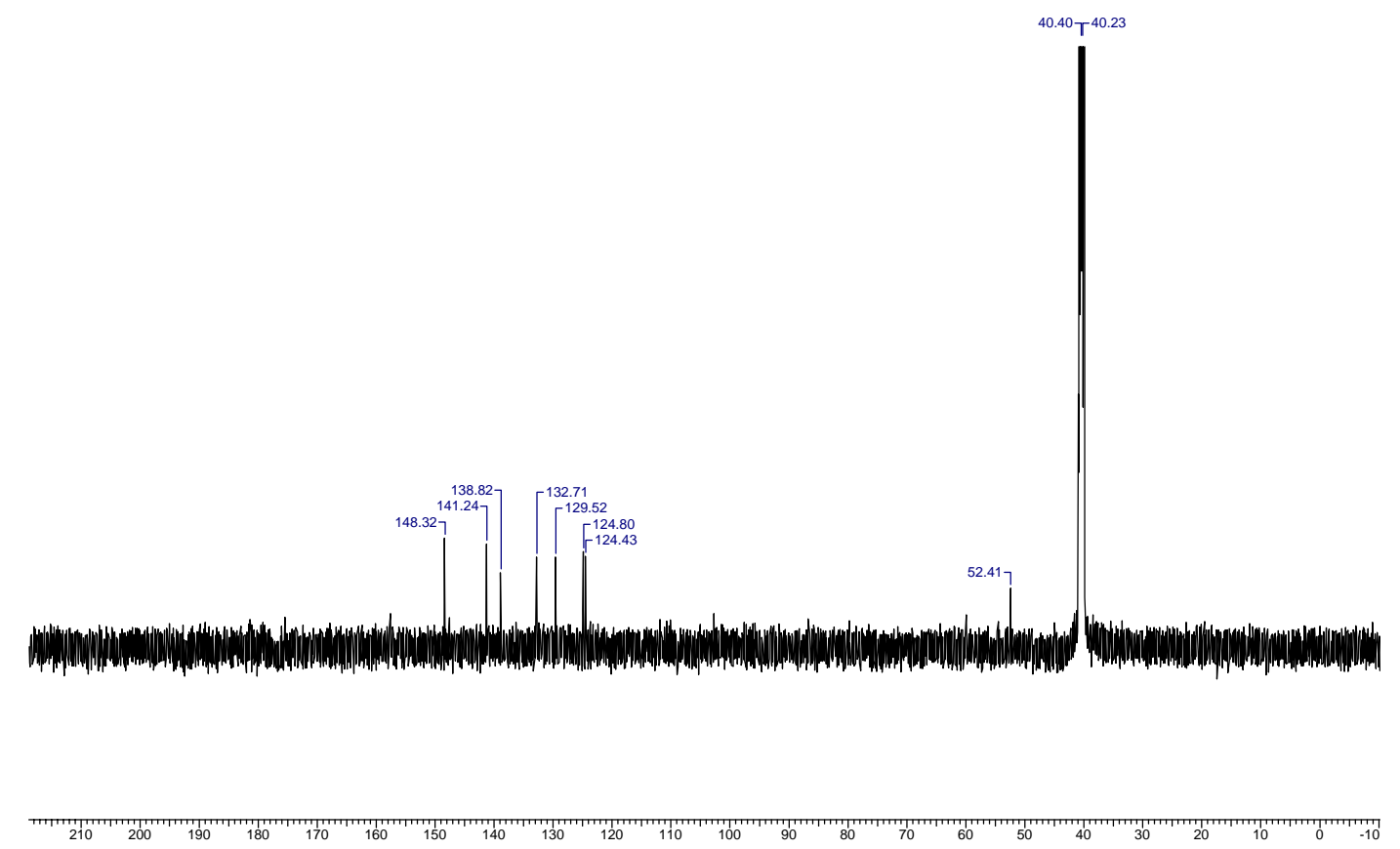
IV. ${ }^{1} \mathrm{H}-\mathrm{NMR}$ and ${ }^{13} \mathrm{C}-\mathrm{NMR}$ of Compound 4

Comp. $4\left({ }^{1} \mathrm{H}-\mathrm{NMR}\right)$
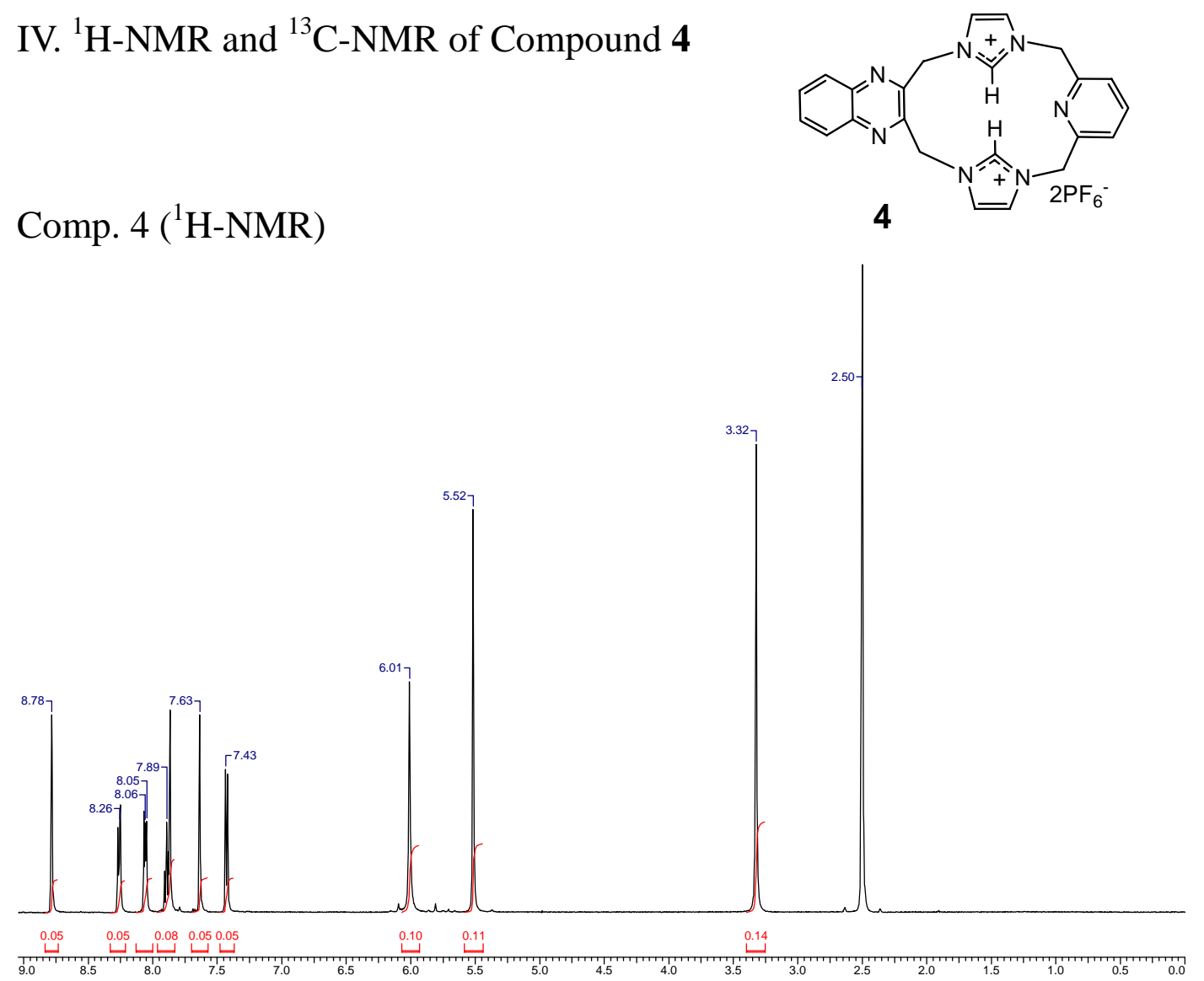

Comp. $4\left({ }^{13} \mathrm{C}-\mathrm{NMR}\right)$

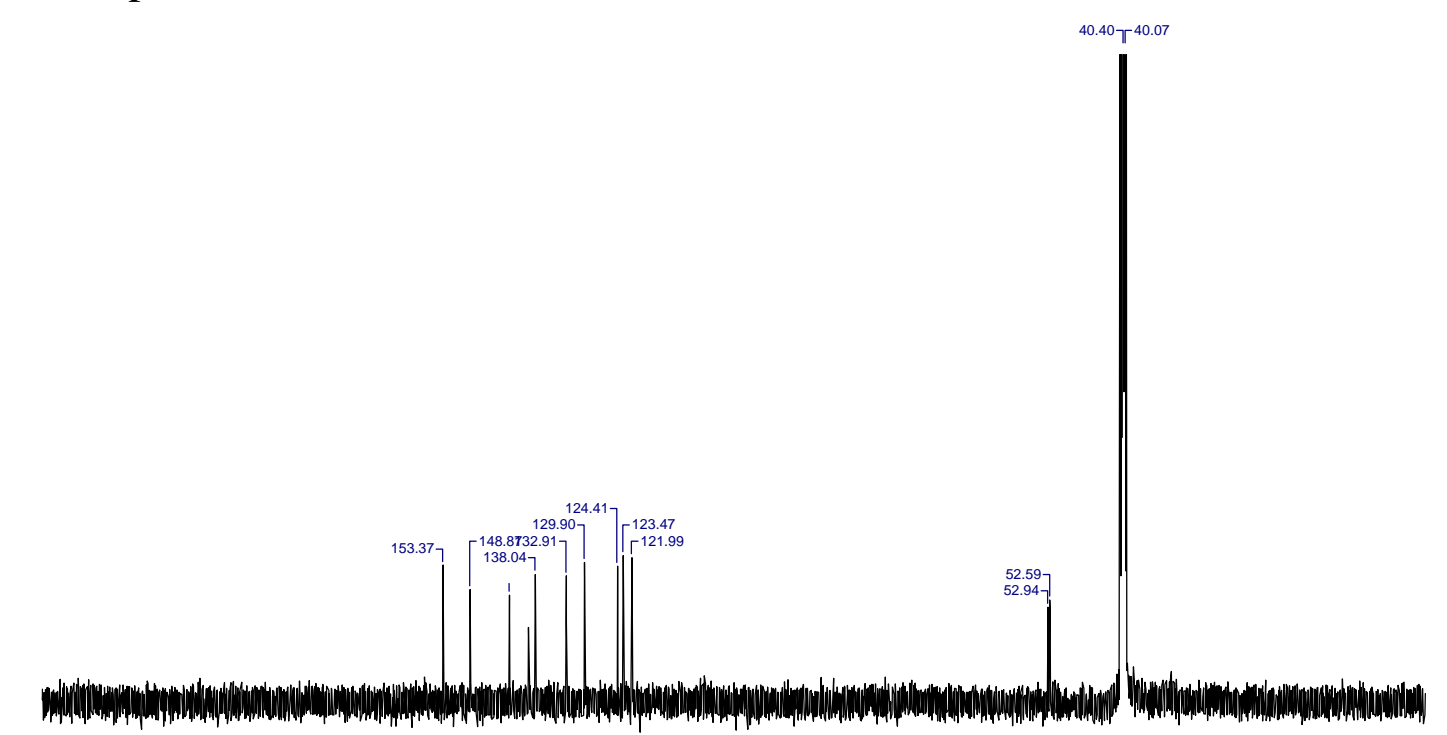

